\title{
Improved PSD and CID on a MALDI TOFMS
}

\author{
Andrew J. Hoteling* \\ Imaging Materials and Media, R\&D, Eastman Kodak Company, Rochester, New York, USA
}

Kevin G. Owens

Department of Chemistry, Drexel University, Philadelphia, Pennsylvania, USA

\begin{abstract}
The influence of several instrument-operating parameters on the product-ion resolution and mass accuracy in matrix-assisted laser desorption/ionization (MALDI) time-of-flight (TOF) post-source decay (PSD) and collision-induced dissociation (CID) experiments is reported. Voltages commonly applied to the reflectron for PSD and CID experiments were found to be non-ideal; optimization of these voltages resulted in better resolution across each segment of the measured PSD spectrum. Mass resolution, calculated as M/ $\triangle M$ (FWHM) for the production peaks, was as high as 2500 . Additionally, precursor-ion selection and segment mass range setup were each found to have dramatic influences on product-ion mass accuracy. An understanding of the influence of these variables aided in the interpretation of $\left(a-\mathrm{NH}_{3}\right)$ and $(\mathrm{b}$ $-\mathrm{NH}_{3}$ ) ions observed in the PSD/CID spectra of a number of peptides. In addition, product ions resulting from coincidence peaks in the precursor-ion selection window were found to be a general problem. With the improvements to resolution and optimization of these mass accuracy variables, the mass accuracy of product ions from MALDI TOF PSD and CID experiments was tested with several reference materials, including the peptides Substance P, bradykinin, angiotensin I, and angiotensin II and the synthetic polymers poly(methyl methacrylate) and polystyrene. The absolute error ( $\mathrm{Da})$ for each test material was, on average, below $0.1 \mathrm{Da}$, demonstrating a significant improvement in mass accuracy using the improved operational parameters and an extension of the use of poly(ethylene glycol) (PEG) as a mass calibrant for the PSD/CID spectra. (J Am Soc Mass Spectrom 2004, 15, 523-535) (C) 2004 American Society for Mass Spectrometry
\end{abstract}

$\mathrm{D}$ ella-Negra and Le Beyec [1] first demonstrated that the reflectron of a TOFMS can be used to mass-analyze metastable ions that form in the first field-free region of the instrument. Standing and co-workers further showed that the mass resolution of the metastable product ions can be improved by acquiring the spectra in segments $[2,3]$, where the reflectron voltage is stepped down with each segment. The application of these technologies for the sequencing of peptides was introduced by Spengler et al. [4-6] and was termed post-source decay (PSD). With the addition of a collision cell after the source of the TOFMS, collisioninduced dissociation (CID) experiments can also be performed [7].

Despite the development of newer instruments such as the Q-TOF [8], there are still many biological [9-15] and synthetic polymer [16-20] applications where PSD and CID on a MALDI TOFMS are useful. Unfortunately, PSD often suffers from poor product-ion resolution; in addition, confidence in the peak mass assign-

Published online February 6, 2004

Address reprint requests to Dr. K. G. Owens, Department of Chemistry, Drexel University, 3141 Chestnut Street, Philadelphia, PA 19104, USA. E-mail: kevin.owens@drexel.edu

*Also at the Department of Chemistry, Drexel University, Pennsylvania, PA 19104, USA ments is often problematic due to mass axis calibration issues.

When the data from a PSD or CID experiment is acquired, the mass range collected for a particular segment often extends beyond the defined mass range of that segment. Under these conditions, the low-mass region of the first segment overlaps with the high-mass region of the second segment. If the data is calibrated correctly, the peaks in these overlap regions should have the same $m / z$ values. When enough segments are collected to cover the mass range, the segments are individually mass calibrated and then "stitched" together to form a complete MS/MS spectrum.

In order to understand the limits of the PSD and CID experiments on a MALDI TOFMS, the focus of our recent work has been to study the factors that contribute to product-ion resolution, precision, and mass accuracy (A. J. Hoteling and K. G. Owens, in preparation). In a number of the experiments described in this paper, PEG was used as the model analyte to study the effects of various instrumental operational modifications. The CID of a selected oligomer of PEG produces product ions that fall into two main series of repeating ions (B and $\mathrm{C}$, in the terminology introduced by Lattimer and co-workers) [21-23], where the spacing between ions within a series is $44 \mathrm{Da}$. These repeating series cover the 
entire mass range of each segment. Further, additional peaks (the D-series) are present in the lower mass segments, which provide added coverage of those segments. The peaks within each series have similar intensities across the individual PSD (or CID) segments, and the product-ion patterns are easily recognizable. The repeating patterns spanning the entire range of each segment are ideal for studying experimental effects on resolution and mass accuracy. Although our interest is primarily in synthetic polymer characterization, several peptide analytes will demonstrate that the operational improvements discussed here can be applied to any type of analysis.

\section{Experimental}

\section{Materials}

Poly(ethylene glycol) 1000 (PEG 1000) was obtained from Aldrich Chemical Co. (Milwaukee, WI). Poly(methyl methacrylate) 1035 (PMMA 1035) was obtained from Polymer Laboratories, Inc. (Amherst, MA), and polystyrene 1200 (PS 1200) was obtained from Polysciences, Inc. (Warrington, PA). The matrix material 1,8,9-Anthracentetriol (dithranol) was obtained from Aldrich Chemical Co., and $\alpha$-cyano-4-hydroxycinnamic acid (CHCA) was obtained from Sigma Chemical Co. (St. Louis, MO). The peptides bradykinin, angiotensin I, angiotensin II, and Substance P were obtained from Sigma Chemical Co. Cationization agents lithium hydroxide $(\mathrm{LiOH})$, sodium trifluoroacetate (NaTFA), and silver trifluoroacetate (AgTFA), were obtained from Aldrich Chemical Co. Cation exchange resin, AG 50W-X8 100-200 mesh in the hydrogen form, was obtained from Bio-Rad Laboratories (Hercules, CA). All matrices were treated with cation-exchange resin prior to use, to reduce the amount of residual sodium and potassium. All other materials were used as received.

\section{Polymer Sample Preparation}

CHCA matrix stock solution was made at a concentration of $0.1 \mathrm{M}$ in methanol, and dithranol stock solution was made at a concentration of $0.1 \mathrm{M}$ in THF (unstabilized). PEG 1000 polymer stock solution was prepared at a concentration of $5 \mathrm{mg} / \mathrm{mL}$ in methanol, and PMMA and PS polymer stock solutions were each prepared at $5 \mathrm{mg} / \mathrm{mL}$ in THF. The cationization agent $(\mathrm{LiOH}$ for PEG, NaTFA for PMMA, and AgTFA for PS) was made at a concentration of $0.025 \mathrm{M}$ in methanol. The MALDI samples were prepared with a volume ratio of 1:7:1 of polymer:matrix:cationization agent, and $0.5 \mu \mathrm{L}$ was deposited on the sample plate and allowed to air dry.

\section{Peptide Sample Preparation}

Matrix (CHCA) stock solution was prepared at a concentration of $10 \mathrm{mg} / \mathrm{mL}$ in a 50:50 (vol/vol) ethanol: acetonitrile solvent. Peptide sample stock solutions were prepared at a concentration of $20 \mathrm{pmol} / \mathrm{uL}$ in $0.1 \%$ trifluoroacetic acid (TFA) in water. The samples were prepared by mixing the matrix stock with the peptide stock in a volume ratio of $1: 1$, resulting in a final peptide concentration of $10 \mathrm{pmol} / \mathrm{uL}$. $1.0 \mathrm{uL}$ of the mixture was deposited on the sample plate and allowed to air dry.

\section{Instrumentation}

MALDI TOF, CID, and PSD experiments were carried out using a TofSpec2E Laser Time-of-Flight mass spectrometer (Micromass, Inc., Manchester, UK), equipped with dual microchannel plate detectors for both linear and reflectron modes, a nitrogen laser (337 $\mathrm{nm}$ ), a timed-ion gate for precursor-ion selection, and a collision cell. All mass spectra were acquired using delayed extraction with a 500 ns delay time and $2600 \mathrm{~V}$ pulse voltage. Helium was used as the collision gas for CID experiments. All data presented were acquired in positive-ion mode with an accelerating voltage of $20 \mathrm{KV}$. For CID experiments, the laser power was set slightly above the threshold of precursor ion formation. For PSD experiments, the laser power was increased (above the threshold of precursor ion formation) until product ions were observed, keeping the most intense product ions on-scale. Each MS/MS (PSD or CID) data set on the TOFMS was collected in nine segments. For the MS/MS experiments on the TofSpec2E instrument, the instrument control software sets the reflectron voltages of the MS/MS segments based on the initial voltage setting for the first segment; the reflectron voltage for the second segment is automatically set to $75 \%$ of that of the first segment. Each subsequent segment reflectron voltage is automatically set to $75 \%$ of the previous segment. Note that the value of the initial reflectron voltage for the first segment was one of the parameters studied in this work.

\section{MS Data Processing}

All PSD and CID spectra were processed in the same manner using MassLynx version 3.4 software (Micromass, Inc.). A second order polynomial was fit through the noise in the spectra and the curve was subtracted such that $10 \%$ of the data points were below the fitted background curve, leaving the peaks on a flat baseline. Spectra were smoothed one time using mean smoothing with a window width of four channels. PSD and CID calibration was performed using product ions from the CID of a single-selected oligomer $(n=22, m / z$ 993) of lithium-cationized PEG 1000 (PEG993), using a threepoint linear fit for each segment. The product ions from PEG993 used as calibrant peaks for each segment are displayed in Table 1, along with the $m / z$ ranges for PEG993 that are used in the "stitching" of data. Note that the data collected in each segment extends beyond the mass ranges listed on both the high and low-mass ends. Table 1 also shows that ions that appear outside the final "stitched" range of a segment are sometimes 
Table 1. The produce-ion peaks of PEG993 used to calibrate each segment

\begin{tabular}{|c|c|c|}
\hline Segment & Calibrant ions & "Stitch" Mass Range \\
\hline \multirow[t]{3}{*}{1} & 947.561 & $993-744$ \\
\hline & 859.509 & \\
\hline & 755.461 & \\
\hline \multirow[t]{3}{*}{2} & 771.457 & $744-558$ \\
\hline & 711.435 & \\
\hline & 623.383 & \\
\hline \multirow[t]{3}{*}{3} & 595.352 & $558-418$ \\
\hline & 535.331 & \\
\hline & 463.273 & \\
\hline \multirow[t]{3}{*}{4} & 447.278 & $418-314$ \\
\hline & 403.252 & \\
\hline & 359.226 & \\
\hline \multirow[t]{3}{*}{5} & 315.200 & $314-235$ \\
\hline & 287.168 & \\
\hline & 271.173 & \\
\hline \multirow[t]{3}{*}{6} & 243.142 & $235-176$ \\
\hline & 227.147 & \\
\hline & 199.116 & \\
\hline \multirow[t]{3}{*}{7} & 183.121 & $176-132$ \\
\hline & 170.113 & \\
\hline & 140.103 & \\
\hline \multirow[t]{3}{*}{8} & 140.103 & 132-99 \\
\hline & 126.087 & \\
\hline & 112.071 & \\
\hline \multirow[t]{3}{*}{9} & 96.076 & $99-0$ \\
\hline & 82.061 & \\
\hline & 68.045 & \\
\hline
\end{tabular}

a Mass range used from each segment in a stitched spectrum for PEG993.

used for mass calibration of the segments. The precision of the mass assignments is generally less than 0.1 Da. The segments of PSD and CID data sets were "stitched" together using the MassLynx software to produce a single MS/MS spectrum.

\section{Results and Discussion}

\section{Influence of Reflectron Voltage}

The focusing of an ion with the reflectron, such that it has the correct trajectory to reach the detector, is dependent on the depth to which the ion penetrates the reflector. Ions that are correctly focused have the narrowest peak width. In order to find the ideal initial reflectron voltage setting, a series of CID spectra were acquired using PEG993. The initial reflectron voltage for the first experiment was set at $26 \mathrm{kV}$ (representing the default instrument conditions for PSD or CID) and was lowered by $500 \mathrm{~V}$ for each subsequent experiment in the series. Figure 1 displays a comparison of the spectra obtained for the second segment of each acquisition. The dotted vertical lines in the figure represent the high-mass and low-mass cut off of the mass range that would be included in a final "stitched" MS/MS spectrum. As demonstrated in Figure 1, as the initial reflectron voltage (and subsequent voltages) is lowered, the focus (resolution) of the ions shifts to different

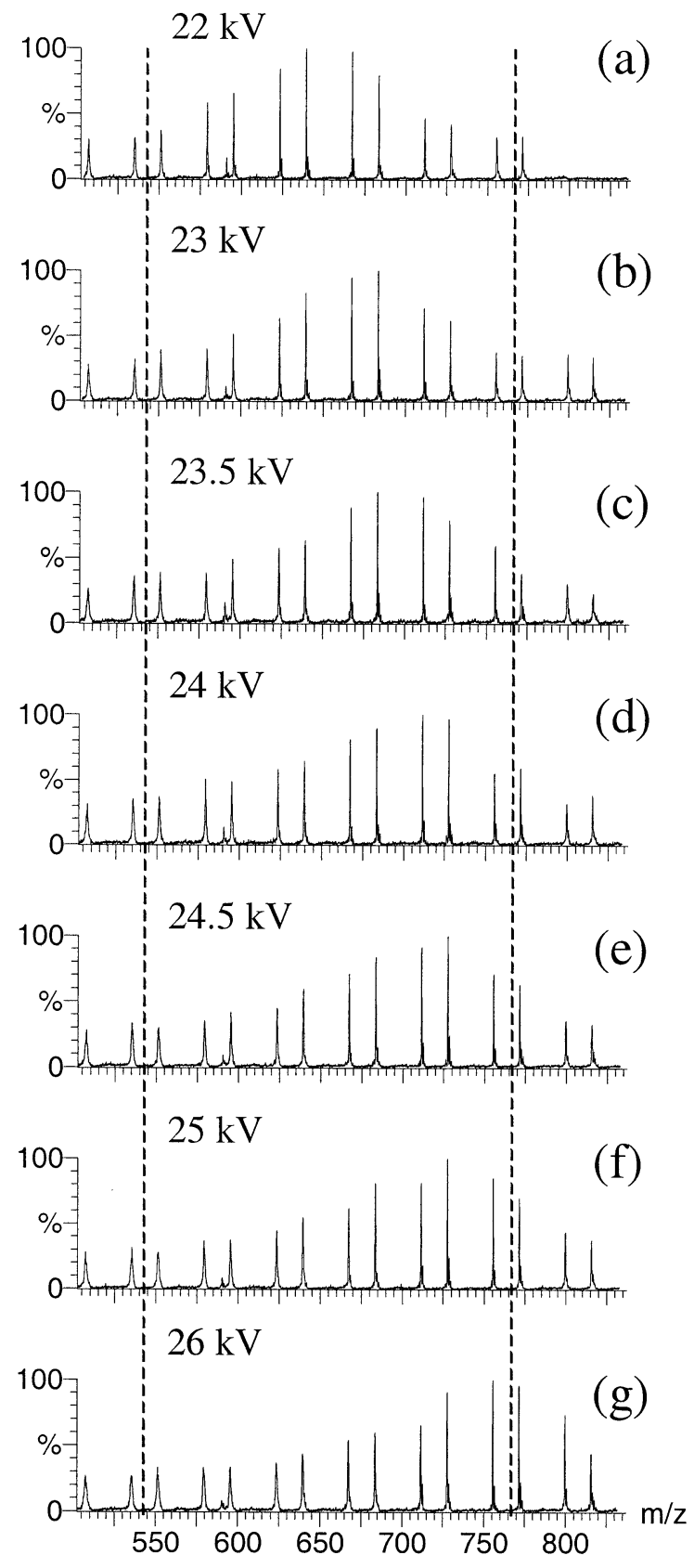

Figure 1. MALDI TOF CID spectra of PEG993 obtained using CHCA matrix and $\mathrm{LiOH}$ for cationization. A comparison of the second segment is displayed where the initial reflectron voltage is: (a) $22 \mathrm{kV}$; (b) $23 \mathrm{kV}$; (c) $23.5 \mathrm{kV}$; (d) $24 \mathrm{kV}$; (e) $24.5 \mathrm{kV}$; (f) $25 \mathrm{kV}$; and (g) $26 \mathrm{kV}$.

kinetic energy, which appears as a shift in the intensity of PEG product ions toward lower mass. The resolution of the low-mass ions improves and that of the highmass ions worsens as initial reflectron voltage is decreased. Note that the highest mass ions in Figure 1a have disappeared completely because they have either exited the back of the reflector or are not focused correctly onto the detector. It appears that the initial reflectron voltage setting in Figure 1a would be the best 


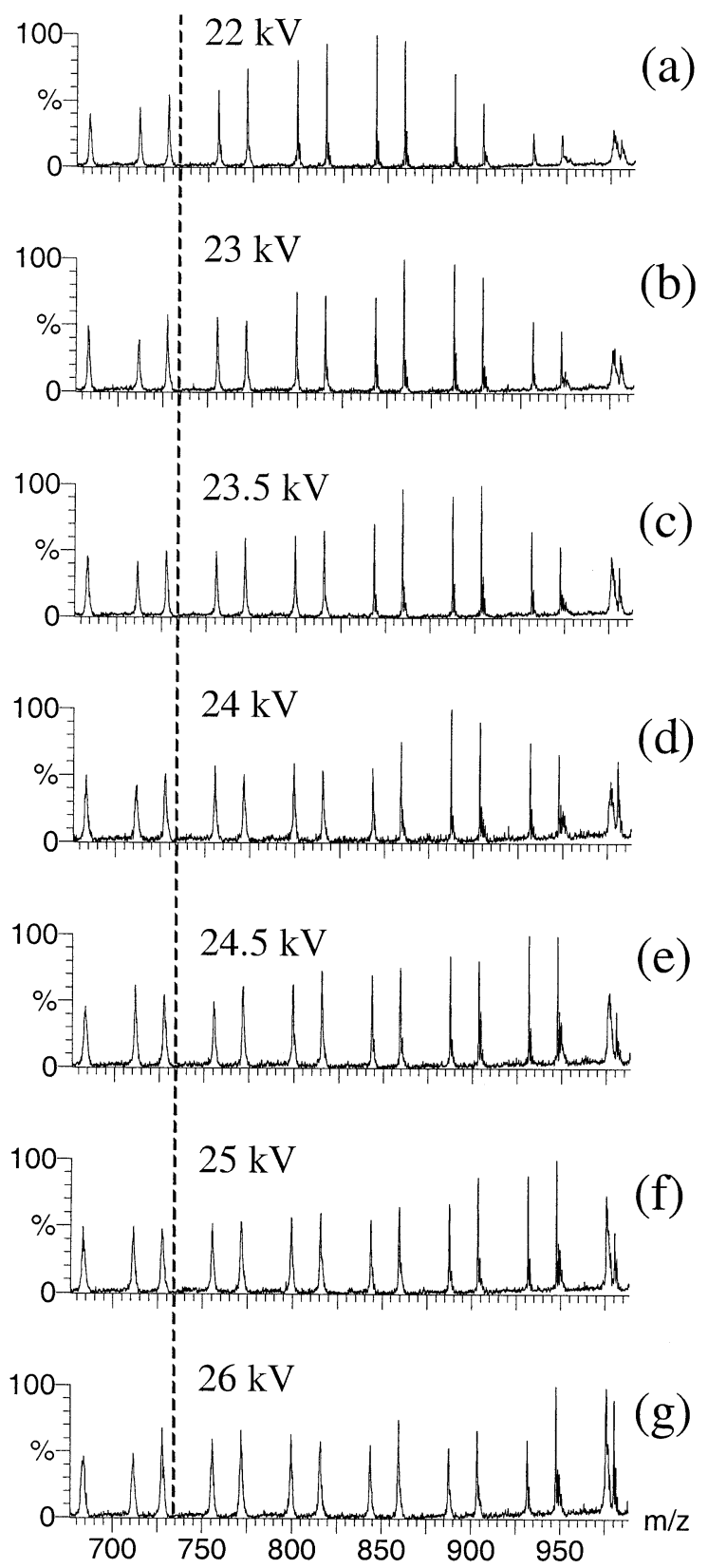

Figure 2. MALDI TOF CID spectra of PEG993 obtained using CHCA matrix and $\mathrm{LiOH}$ for cationization. A comparison of the first segment is displayed where the initial reflectron voltage is: (a) $22 \mathrm{kV}$; (b) $23 \mathrm{kV}$; (c) $23.5 \mathrm{kV}$; (d) $24 \mathrm{kV}$; (e) $24.5 \mathrm{kV}$; (f) $25 \mathrm{kV}$; and (g) $26 \mathrm{kV}$.

in terms of producing the best focus of product ions across the segment, which appears as a centered intensity distribution. However, the effect of this reflectron voltage setting on the data collected in the first segment also needs to be considered.

The same comparison from Figure 1 is repeated in Figure 2 where the first segment of each MS/MS acquisition is displayed. In this case, the single vertical dotted line represents the low-mass cutoff of the mass range that would be included in the final "stitched" MS/MS spectrum. Note that in the first segment, all of the high-mass ions need to be included in the final "stitched" spectrum. The initial reflectron voltage that appeared to be the best from Figure 1 would not be ideal for the first segment because the resolution and apparent intensity of the highest mass ions has greatly diminished. The decrease in peak intensity (height) may be explained by a tradeoff with resolution, and it is possible that the peak areas are the same. However, because of the air-dry sample preparation method, poor peak area reproducibility would preclude a quantitative evaluation. The initial reflectron voltage of $23.5 \mathrm{kV}$ appears to be a good compromise for both the highmass end of the first segment and the overall resolution of the remaining segments. This initial reflectron voltage was used in all subsequent data reported here and is referred to as the new PSD and CID condition.

Note that the default instrument conditions, with the initial reflectron voltage of $26 \mathrm{kV}$ for the first segment, were based on the ideal conditions for precursor-ion resolution. At $26 \mathrm{kV}$, the resolution of the precursor-ion, as well as the regions just above and just below the mass of the precursor-ion are focused because they are similar in kinetic energy to the precursor-ion. The resolution falls off in moving toward either higher or lower mass. Essentially, there is a distribution of resolution that is centered about the precursor-ion mass. This is not the ideal way to set up data collection for a PSD or CID experiment because the product ions, rather than the precursor-ion, are the main interest in the spectrum. Under these default conditions, the product ions at the low-mass end of the segment have very poor resolution. Also, the region above the mass of the precursor has good resolution, which is not needed. With this initial reflectron voltage, the high-mass peaks that extend beyond the defined range of a segment have much better resolution than the same peaks at the low-mass end of the previous segment (the overlap region). As a result, some of the poorly resolved peaks from the low-mass end of one segment are used in the final "stitched" spectrum instead of the higher resolution peaks from the high-mass end of the next segment. Using an initial reflectron voltage of $23.5 \mathrm{kV}$ greatly improved resolution in the overlap regions and, in addition, improved "stitching". To demonstrate the resolution improvement, Figure 3 displays the lowmass region of Segment 1 comparing initial reflectron voltages $26 \mathrm{kV}$ and $23.5 \mathrm{kV}$ for PEG993 (CID). The resolution of representative peaks across the mass ranges of the first and second segments of these two data sets were compared and are displayed in Table 2. As can be seen from the table, all but one peak displayed improved resolution.

It is worth noting that, when the initial reflectron voltage was set at $22 \mathrm{kV}$ (Figure 1a), and the high-mass peaks began to disappear, the peak at $\mathrm{m} / \mathrm{z} 551$ was still not isotopically resolved. This suggests that setting the reflectron voltage for the second segment at $75 \%$ of that of the first segment is beyond the ideal focusing capability of the reflectron. In order to obtain isotopic 

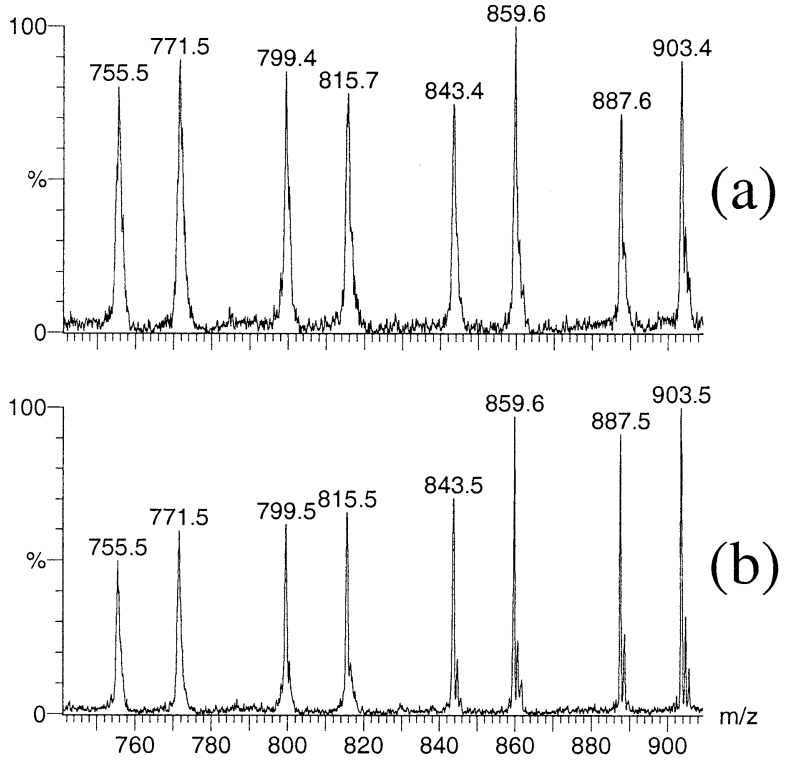

Figure 3. A comparison of the resolution observed in the lowmass region of Segment 1 of the CID spectrum of PEG993 for two different initial reflectron voltages: (a) $26 \mathrm{kV}$ and (b) $23.5 \mathrm{kV}$.

resolution for all peaks in all segments, an $80 \%$ decrementation of reflectron voltage for subsequent segments might be more appropriate. However, this $75 \%$ decrementation of reflectron voltage is a current software limitation of the instrument. In order to obtain isotopic resolution across the entire mass range of each segment, there would need to be an increase in the number of segments and, therefore, a compromise in spectral acquisition time. With regard to product ion resolution, this indicates an opportunity for further improvement beyond that already demonstrated in Figure 3 and Table 2.

\section{Precursor Ion Selection}

One of the limitations of PSD and CID experiments is the resolution of the precursor-ion selection. On the instrument used in these investigations, a Bradbury-

Table 2. The mass resolution $(\mathrm{M} / \Delta \mathrm{M})$ of representative product ions in the first two segments, comparing the initial reflectron voltage of $26 \mathrm{kV}$ versus $23.5 \mathrm{kV}$

\begin{tabular}{lcccc}
\hline Segment & $\begin{array}{c}\text { Product } \\
\text { ion } m / z\end{array}$ & $\begin{array}{c}26 \mathrm{kV} \\
\text { resolution } \\
\mathrm{m} / \Delta \mathrm{m}(50 \%)\end{array}$ & $\begin{array}{c}23.5 \mathrm{kV} \\
\text { resolution } \\
\mathrm{m} / \Delta \mathrm{m}(50 \%)\end{array}$ & $\begin{array}{c}\text { Percent } \\
\text { improve- } \\
\text { ment }\end{array}$ \\
\hline \hline 1 & 947 & 1909 & 2332 & 22 \\
1 & 903 & 1280 & 2515 & 96 \\
1 & 859 & 1057 & 2070 & 96 \\
1 & 799 & 753 & 1058 & 41 \\
1 & 771 & 497 & 750 & 51 \\
2 & 755 & 2138 & 1727 & -19 \\
2 & 711 & 1439 & 2257 & 57 \\
2 & 639 & 661 & 1111 & 68 \\
2 & 595 & 551 & 810 & 47 \\
2 & 551 & 393 & 586 & 49 \\
\hline
\end{tabular}
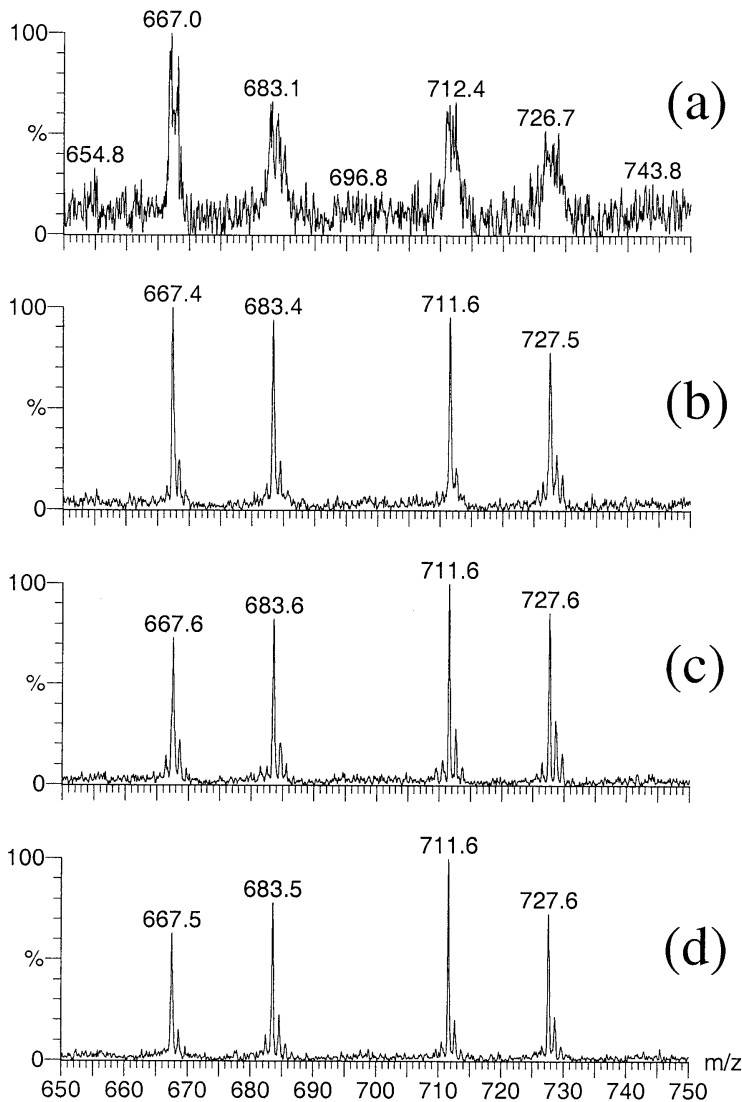

Figure 4. Expanded view of the $660-740$ Da mass range to demonstrate the effect of precursor-ion selection window width on resolution and sensitivity. The precursor-ion is centered within the selection window for each spectrum. Total width of the selection window is: (a) $12 \mathrm{Da}$; (b) $25 \mathrm{Da}$; (c) $37 \mathrm{Da}$; and (d) $49 \mathrm{Da}$.

Neilson timed ion gate is used for precursor-ion selection. The width (in Daltons) of the precursor-ion selection window is dependent upon mass. For instance, the narrowest window width possible for a precursor mass of $500 \mathrm{Da}$ will be narrower than the narrowest window width for a precursor mass of 1000 . At mass 1000, the narrowest width of the selection window is approximately $\pm 6 \mathrm{Da}$, which is noticeably worse than most MS/MS techniques performed on other types of instruments. Figure 4 displays the effect of the width of the precursor-ion selection window on the sensitivity and resolution of CID peaks of PEG 993 where data from the second segment in the $m / z$ range $660-740$ is displayed. The selection can be narrowed to as low as 12 Da (i.e., $\pm 6 \mathrm{Da})$ at this mass; however, the resolution of the product ions is severely compromised. The data in Figure 4 show that any of the other selection width settings yield good product-ion resolution; the only consideration would be whether neighboring ions are adequately excluded from the precursor-ion selection window. Aside from the limitation of the width of the precursor-ion selection window, additional details of the precursor-ion selection were found to have a dramatic influence on PSD and/or CID product-ion mass accuracy. 

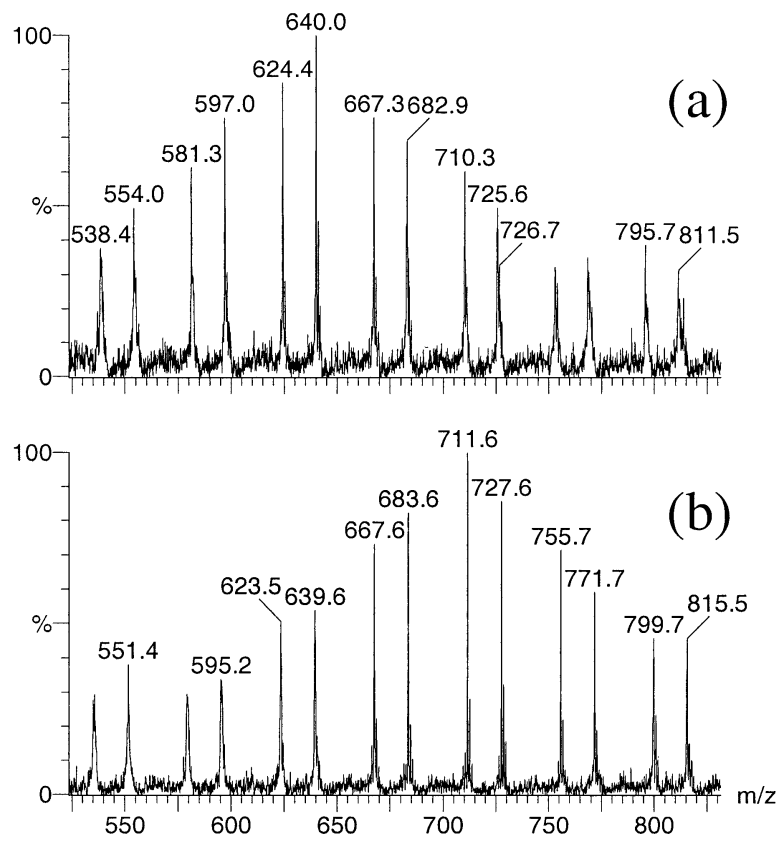

Figure 5. The effect of centering the selected mass within the selection window on mass-measurement accuracy. In panel (a), $\mathrm{m} / \mathrm{z} 993$ is selected with the window set as 982-1024 (the selected mass is in the low-mass end of the window); in panel (b), $\mathrm{m} / \mathrm{z} 993$ is selected with the window set as $977-1009$ (the selected mass is centered).

The position of the precursor-ion within the selection window was also found to be critical to mass accuracy in PSD and CID experiments. PEG993 was used to study this parameter. A region of the CID spectra from two sets of precursor-ion selection conditions is displayed in Figure 5. The first selection condition is where the $m / z 993$ peak is at the low-mass end of the selection window (Figure 5a). This condition mimics the situation where a precursor-ion is mass selected (e.g., an imaginary peak at $m / z$ 1008) and a second peak (i.e., $m / z$ 993) also falls within that selected window. The second selection condition is where ion $m / z$ 993, is centered within the selection window (Figure $5 b$ ), which is the situation where the ion at $m / z 993$ is the precursor-ion of interest. Note that the product-ion peaks from PEG, shown in Figure 5a, are not mass calibrated correctly. For example, the peak at $\mathrm{m} / \mathrm{z}$ 624.4 should be 623.4 . This data demonstrates that if more than one precursor-ion peak falls within the selection window, that only the product ions of the precursor-ion that is centered will be mass calibrated correctly. Note that, in addition to the incorrect mass calibration, there is an apparent shift in the focus (resolution) of the ions toward lower mass (lower kinetic energy). This is likely caused by an "edge effect" where the kinetic energy of those ions spatially close to the ion gate is perturbed by the voltage applied to close the ion gate.

\section{Coincidence Peaks}

There are situations, especially in PSD spectra, where product-ion peaks are present that cannot be inter-
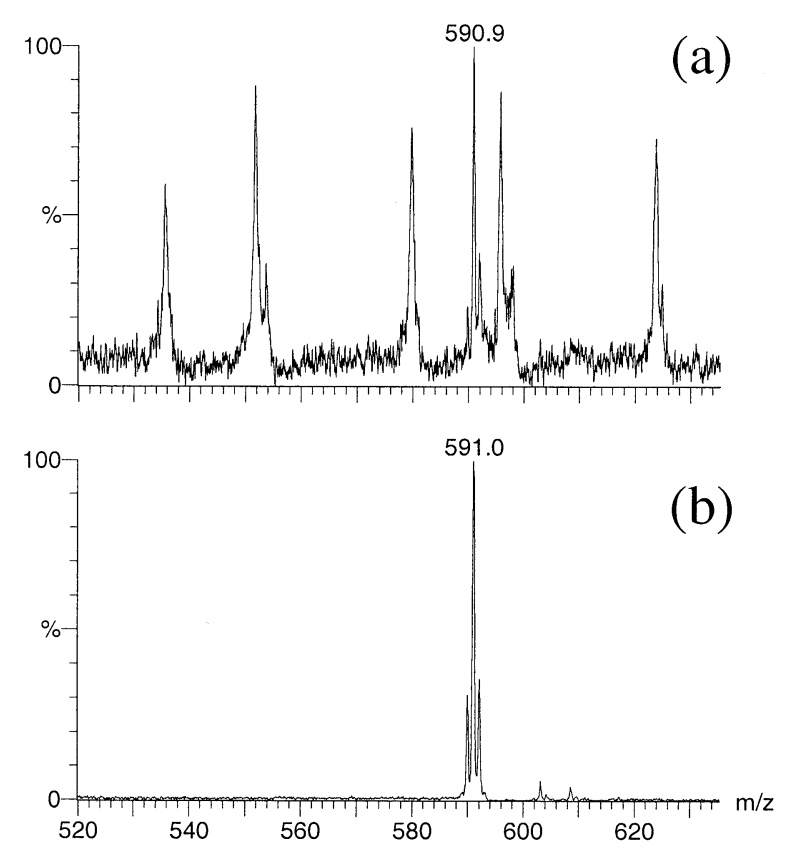

Figure 6. Data from the second PSD segment for: (a) PEG993 sample and (b) sample blank (CHCA + $\mathrm{LiOH}$ only) to demonstrate the "ghost" peak at $m / z 591$.

preted. An example of this can be seen in the second segment of the PSD spectrum of PEG993 displayed in Figure 6a. The peak at $m / z 590.9$ is difficult to interpret, and it will be referred to as a "ghost" or "coincidence" peak. An additional control experiment was run where the matrix and cationization agent were mixed without the PEG analyte and deposited onto the sample plate (blank). The same exact instrument conditions were used, including the same selection window for the blank that was used for the PEG993 spectrum. PSD analysis of the blank resulted in a product-ion peak at $\mathrm{m} / \mathrm{z}$ 591, identical to that found in the PEG993 spectrum (Figure 6b). Under single-stage MS conditions, where the precursor-ion of PEG 993 was selected, there did not appear to be any other peaks present in the selection window. However, for PSD analysis, the detector gain and laser power is increased in order to obtain measurable product ions. Under these PSD conditions, a cluster ion of CHCA matrix with Li cations is observed to fall within the precursor-ion selection window. This cluster ion was observed to dissociate into a number of product ions that appear as ghost peaks in the PSD or CID spectrum when PSD or CID analysis was performed. To identify the $m / z 591$ peak, additional experiments were performed, beginning with the single-stage MS spectrum for the blank sample prep described above, as displayed in Figure 7a. Note that a CHCA-Li cluster is observed at $m / z$ 982. The $m / z 982$ peak from the blank was centered in the selection window and the PSD spectrum was acquired, displayed in Figure $7 \mathrm{~b}$. With the $m / z 982$ cluster ion centered and the data properly calibrated, the ghost peak is found to have a $\mathrm{m} / \mathrm{z}$ value of 592, which corresponds to the loss of $2 \mathrm{CHCA}$ 


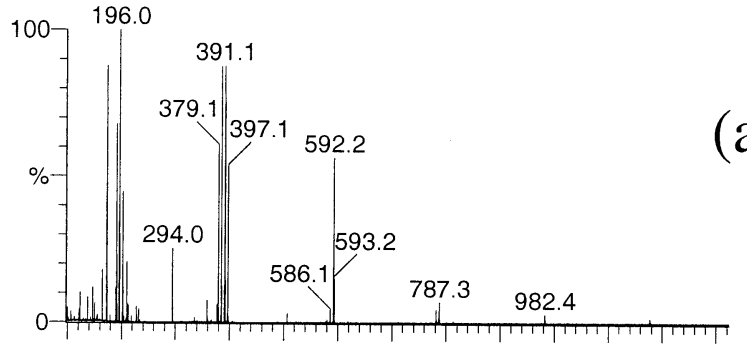

(a)

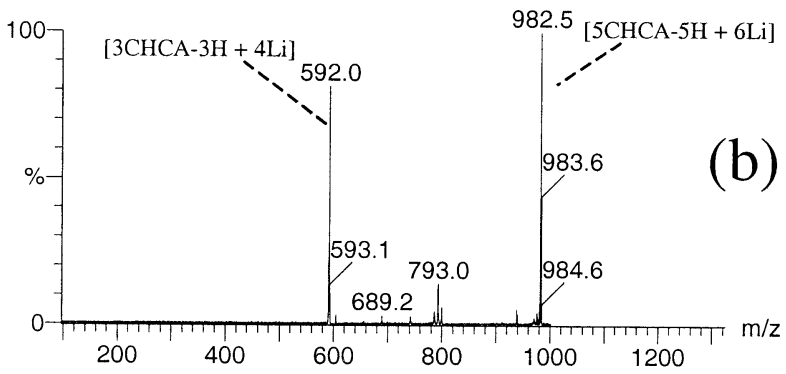

Figure 7. Spectra demonstrating the clusters of CHCA matrix with lithium cations observed: (a) MALDI TOF MS of sample blank (CHCA + LiOH only); and (b) PSD spectrum of the $m / z 982$ cluster centered in the selection window.

$+2 \mathrm{Li}$ from the precursor cluster ion [5CHCA $-5 \mathrm{H}+$ 6Li]. This set of experiments confirms that the ghost peak is coming from a species that was not apparent in the original precursor-ion selection window. As expected from the previous discussion, the mass marking of $\mathrm{m} / \mathrm{z} 591$ for the ghost peak was incorrect. This is a general problem with MALDI PSD and CID that can complicate spectra collected from any type of analyte.

\section{Segment Mass Ranges}

When setting up a PSD or CID experiment on the TofSpec2E instrument, the mass ranges acquired for each segment are set up independently from the precursor-ion selection described above. The manner in which the PSD (or CID) segment mass ranges are set up was also found to have a significant influence on the mass accuracy of product ions. In the data acquisition software (Masslynx version 3.4), the acquisition mass ranges for the segments are based on the input of a beginning mass, which defines the high-mass end of the first segment. The mass range for the first segment begins at the entered beginning mass and extends to $75 \%$ of that mass. The second segment begins at the mass value that ended the first segment and extends to $75 \%$ of that value. Each of the subsequent segments decrements in this manner, except for the last segment that extends to $0 \mathrm{Da}$. The described mass ranges define the ranges that are included from each segment in a "stitched" MS/MS spectrum. In the following discussion, the term "beginning mass" will refer to the mass that was input to the software to define the high-mass limit of the first segment. This parameter is indepen-

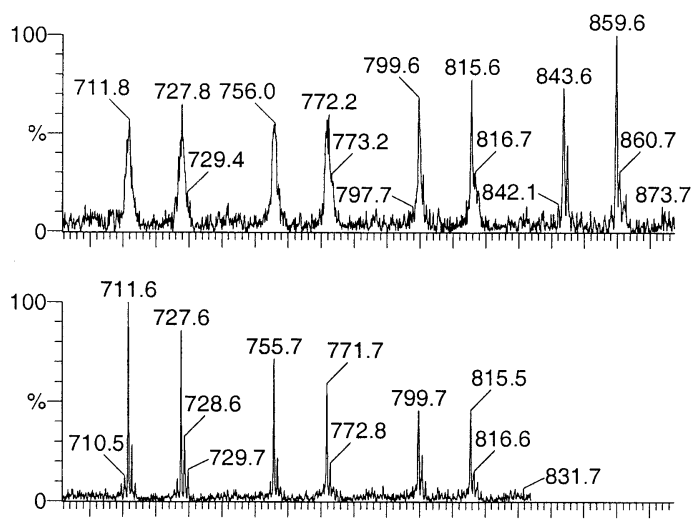

(a)

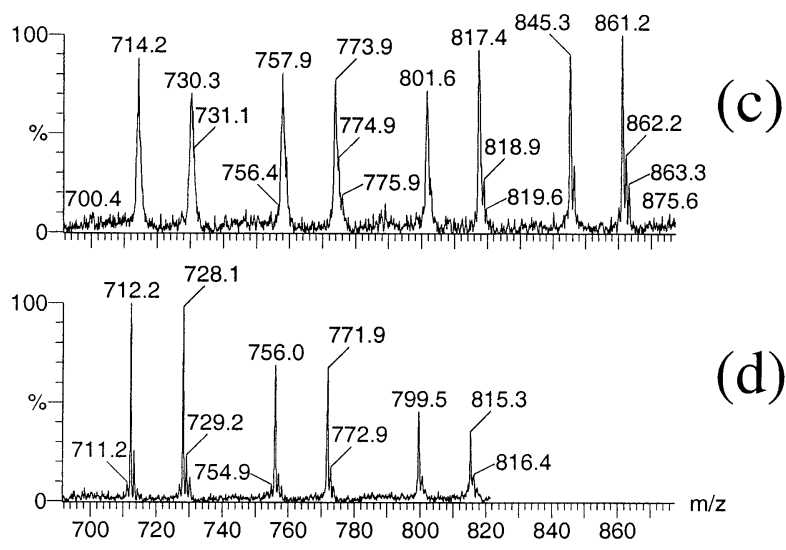

Figure 8. The effect of PSD mass-range setup on the calibration of peaks in the overlap region for PEG993: (a) beginning mass 1005, Segment 1; (b) beginning mass 1005, Segment 2; (c) beginning 990, Segment 1; and (d) beginning mass 990, Segment 2. Data calibrated with separate PEG993 CID with beginning mass 1005.

dent of the precursor-ion selection described in the section above. All spectra shown below were acquired with the precursor-ion selection held constant, where the selected precursor-ion is centered within the selection window. Note that for all of the experiments described in the "precursor-ion selection" section, the beginning mass was held constant, while the selection window was varied.

The overlap regions of the first and second segments from two sets of beginning mass setup conditions are displayed in Figure 8, where PEG993 was the precursorion. Figure $8 \mathrm{a}$ and $\mathrm{b}$ are the first and second segments of a CID data set where the beginning mass was set at 1005 Da. Figure $8 \mathrm{c}$ and $\mathrm{d}$ are the first and second segments of a CID data set where the beginning mass was set at 990 Da. Both data sets were mass calibrated using a separate CID spectrum of PEG993, in which the precursor-ion was centered in the selection window and beginning mass was set at $1005 \mathrm{Da}$. Note that the mass markings of the overlap region in Figure 8a and b agree well, while the mass markings for the overlap region of Figure $8 c$ and $d$ show large differences. For example, the expected product ion at $815.5 \mathrm{Da}$ is measured as 815.5 and 815.5 in Figure 8a and b, respectively, where the same ion is measured as 817.4 and 815.3 in Figure $8 \mathrm{c}$ and $d$, 
respectively. The same set of data was calibrated with a separate CID spectrum of PEG993, in which the precursor-ion was centered and the beginning mass was set at $990 \mathrm{Da}$. The peaks in the overlap regions for the data collected beginning at 990 agreed well, while those from the data collected beginning at 1005 showed large differences (vide infra).

It is also worth noting that the selected beginning mass has an influence on the resolution and sensitivity of the low-mass peaks of each segment. For example, the peak labeled 711.8 in Figure 8a and 714.2 in Figure $8 \mathrm{c}$ represent the same product ion (ignoring the calibration error). Note that both the resolution and signal-to-noise ratio of the peak in Figure $8 \mathrm{c}$ are noticeably better than that of the peak in Figure 8a. As previously mentioned, the mass ranges that are acquired for each segment of the PSD or CID data set actually extend beyond those defined by the beginning mass. This is also true of the first (highest mass) segment, which contains the precursor-ion. Because the ranges that are acquired actually extend beyond the defined mass ranges, the recommended practice of setting the beginning mass approximately $10 \mathrm{Da}$ higher in mass than the precursor-ion mass is not necessary. The data in Figure 8 demonstrates that by setting up the beginning mass for PSD or CID segments at or slightly below the $\mathrm{m} / \mathrm{z}$ for the precursorion mass, the resolution and sensitivity across the mass range of each segment is improved.

As demonstrated in Figure 8, the beginning mass is an important parameter. The importance of this point is emphasized when the precursor-ion mass for the calibrant and analyte of interest are different. Figure 9 shows the overlap region of Segment 1 (Figure 9a) and Segment 2 (Figure 9b), of a CID data set of the $n=23$ oligomer of lithium cationized PEG at $\mathrm{m} / \mathrm{z} 1037$ (PEG1037), where the beginning mass was set $5 \mathrm{Da}$ below the $\mathrm{m} / \mathrm{z}$ of the precursor-ion. The data in Figure 9 was calibrated using PEG993, where the beginning mass was also 5 Da below the $\mathrm{m} / \mathrm{z}$ of the precursor-ion. Note that the mass markings of these overlap region peaks agree well. In comparison, Figure 10 shows the same overlap region for a CID data set of PEG1037, where the beginning mass was set to be identical to the $\mathrm{m} / \mathrm{z}$ of the precursor-ion. The data in Figure 10 was also calibrated using PEG993, where the beginning mass was $5 \mathrm{Da}$ below the $\mathrm{m} / \mathrm{z}$ of the precursor-ion. The mass markings of the peaks in the overlap region have differences as large as $1 \mathrm{Da}$. In this case, the manner in which the segment mass ranges are set up was not kept consistent, which resulted in errors in the mass markings in the overlap regions. The agreement of the mass markings of this overlap region demonstrates that it is important to be consistent with setting the beginning mass. With larger differences in calibrant- and analyteprecursor masses, this type of error can easily occur, which can lead to significant mass accuracy errors.
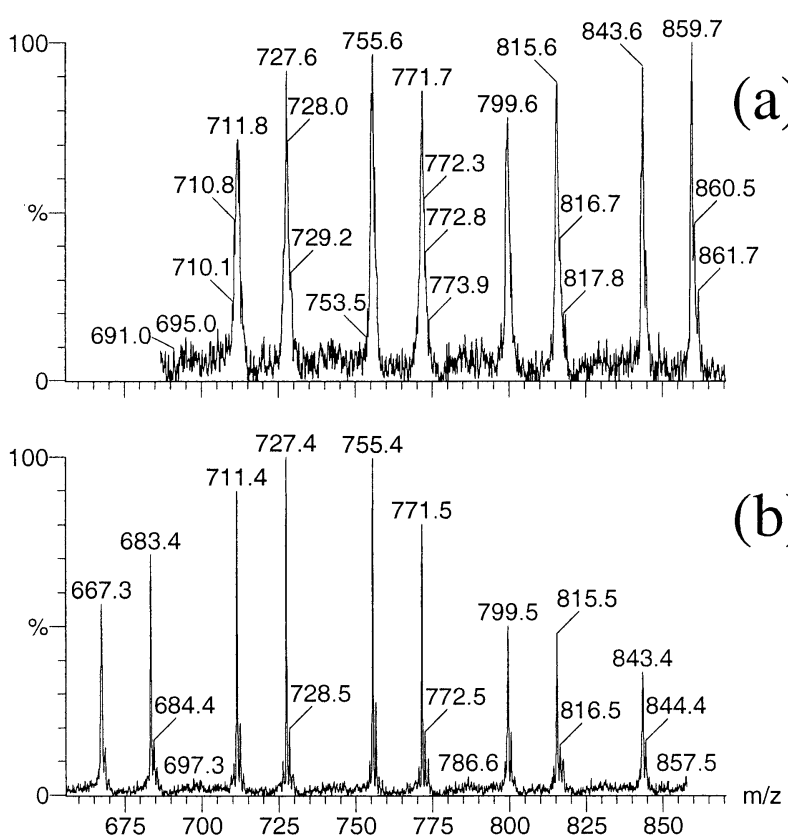

Figure 9. Demonstration of the mass calibration in the overlap region of (a) Segment 1 and (b) Segment 2 of PEG1037, where the first-segment beginning mass is 5 Da below the precursor-ion mass. Data calibrated with separate PEG993 CID with beginning mass 5 Da below the precursor-ion mass.

\section{Product-Ion Mass Accuracy}

The three critical parameters described above were all incorporated into a new set of operating conditions used for acquiring PSD or CID data in which the initial
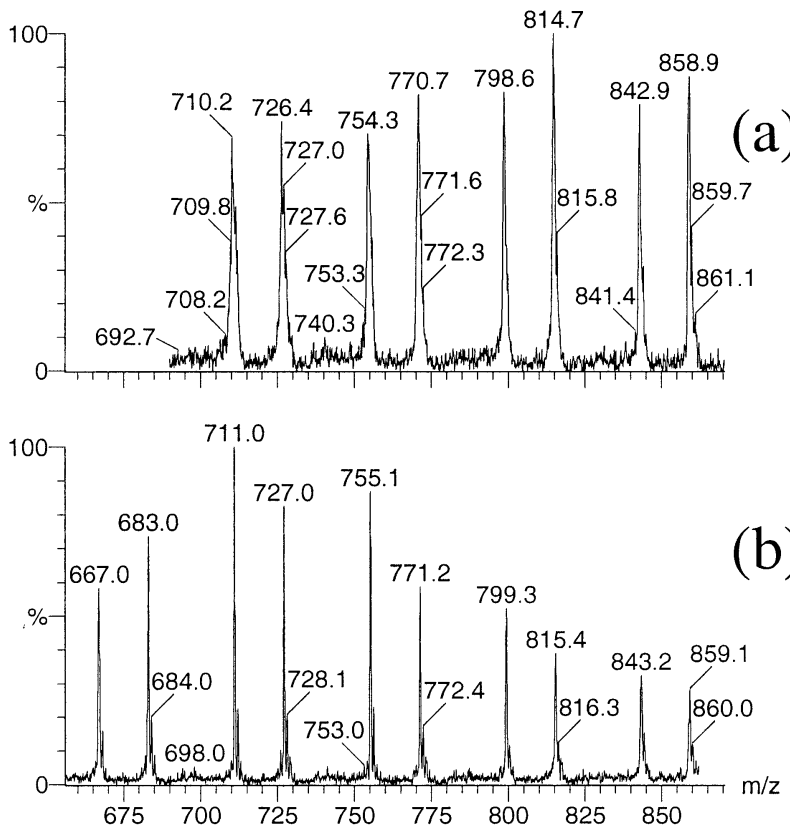

Figure 10. Demonstration of the mass calibration in the overlap region of (a) Segment 1 and (b) Segment 2 of PEG1037, where the first-segment beginning mass is equal to the precursor-ion mass. Data calibrated with separate PEG993 CID with beginning mass 5 Da below the precursor-ion mass. 


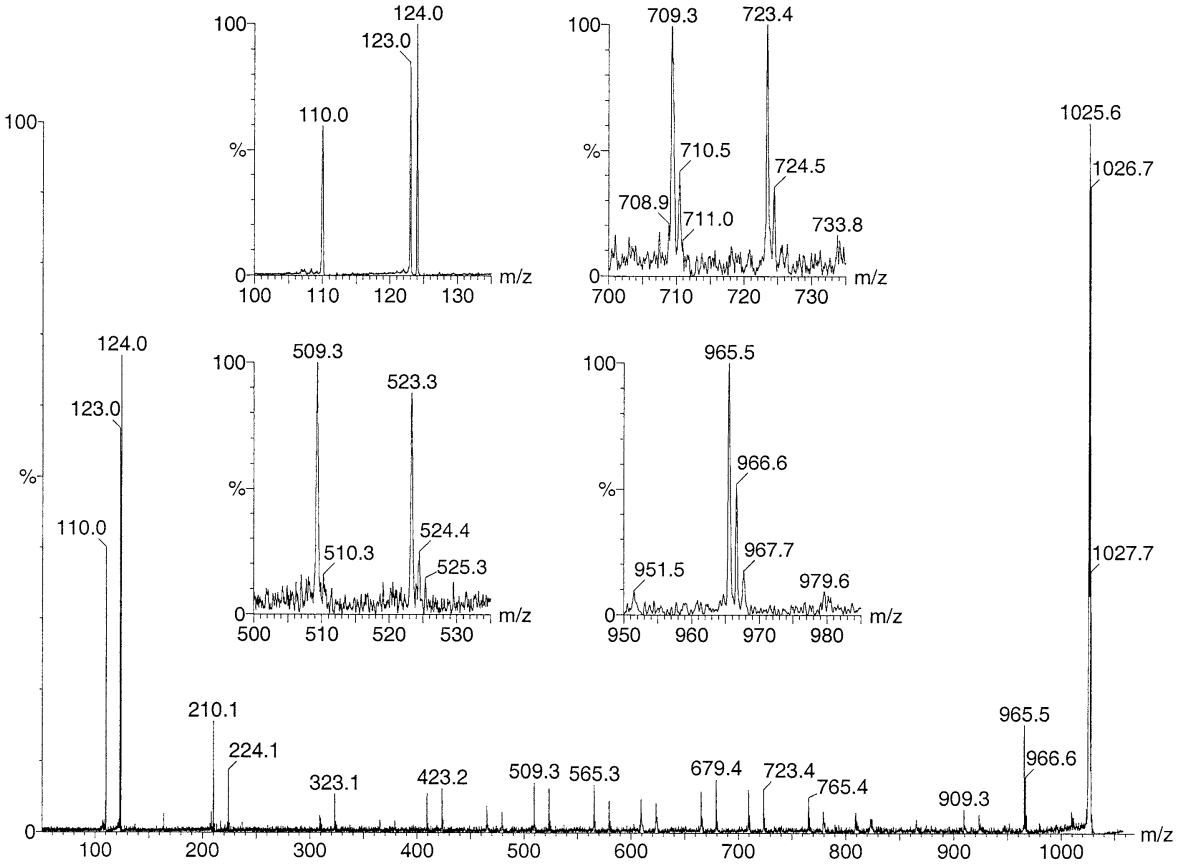

Figure 11. Stitched MALDI TOF CID spectrum of the $m / z 1025$ oligomer of Na cationized PMMA.

reflectron voltage was $23.5 \mathrm{kV}$, the precursor-ion was centered in the selection window, and the beginning mass was set at the $\mathrm{m} / \mathrm{z}$ value of the precursor-ion of interest. Using these new operating conditions, several analytes were tested using PEG993 as the calibrant, and their product-ion mass accuracy was assessed. This demonstrates the extension of the use of PEG993 as a calibrant for PSD and CID of other synthetic polymers, as well as with biological molecules (i.e., peptides). The first set of examples is used to examine the application of PEG calibration toward other polymer types.

Two structurally different polymer systems were examined. Figure 11 displays the "stitched" CID spectrum of the $n=10(\mathrm{~m} / z$ 1025) oligomer from the polymer distribution of sodium-cationized poly(methyl methacrylate) (PMMA). The inset plots zoom in on regions of the spectrum to highlight the observed mass resolution. The product ions described by Scrivens and co-workers [24] were used to calculate the expected masses, which are compared with their corresponding measured values in Table 3. A second example of a polymer system that was examined by MALDI TOF CID using PEG993 calibration was polystyrene (PS). The previous MS/MS examination of this polymer system by Scrivens and co-workers [25] provides the basis for the expected product-ion values used here. The MALDI TOF CID spectrum of the $n=10$ oligomer of silver cationized PS $1200(\mathrm{~m} / \mathrm{z} 1205)$ was obtained and the product-ion masses were assessed. [Due to length considerations, only one polymer and one peptide example are included in the figures and tables. The CID spectrum of PS, the PSD and CID spectra of the listed peptides and the tabulated mass-accuracy data are provided as supplemental information at the following website: www.chemistry.drexel.edu/people/owens/ supplementalinfo.htm]. For PMMA, the average error (absolute value $\Delta m / z$ ) was $0.053 \mathrm{Da}$. For PS, the average error (absolute value $\Delta \mathrm{m} / \mathrm{z}$ ) was $0.069 \mathrm{Da}$. It is worth noting that for the examples demonstrated here, the absolute value of the difference in mass of the calculated values and the measured values appears to be constant through the entire mass range. The polymer examples examined here represent dramatic differences in structure from that of the calibrant PEG. Also, as noted in the experimental section, the sample preparation conditions for these polymers are quite different from that of the calibrant PEG with regard to both the

Table 3. Mass accuracy of the product ions of the $\mathrm{m} / z 1025$ oligomer of sodium cationized PMMA

\begin{tabular}{|c|c|c|c|c|c|}
\hline $\begin{array}{l}\text { Expected } \\
m / z \text { (Da) }\end{array}$ & $\begin{array}{l}\text { Actual } \\
m / z(D a)\end{array}$ & $\begin{array}{c}\Delta m / z \\
(\mathrm{Da})\end{array}$ & $\begin{array}{r}\text { Expected } \\
m / z \text { (Da) }\end{array}$ & $\begin{array}{l}\text { Actual } \\
m / z(\mathrm{Da})\end{array}$ & $\begin{array}{c}\Delta m / z \\
(\mathrm{Da})\end{array}$ \\
\hline 110.034 & 110.038 & 0.004 & 579.278 & 579.428 & 0.150 \\
\hline 123.042 & 123.039 & -0.003 & 609.289 & 609.389 & 0.100 \\
\hline 124.050 & 124.039 & -0.011 & 623.304 & 623.277 & -0.027 \\
\hline 223.095 & 223.051 & -0.044 & 665.310 & 665.256 & -0.054 \\
\hline 224.102 & 224.105 & 0.003 & 679.330 & 679.374 & 0.044 \\
\hline 309.131 & 309.118 & -0.013 & 709.341 & 709.344 & 0.003 \\
\hline 323.147 & 323.142 & -0.005 & 723.357 & 723.420 & 0.063 \\
\hline 324.155 & 324.156 & 0.001 & 765.370 & 765.441 & 0.071 \\
\hline 409.184 & 409.190 & 0.006 & 779.380 & 779.170 & -0.210 \\
\hline 423.199 & 423.238 & 0.039 & 809.394 & 809.365 & -0.029 \\
\hline 465.210 & 465.182 & -0.028 & 823.409 & 823.265 & -0.144 \\
\hline 479.230 & 479.330 & 0.100 & 865.420 & 865.381 & -0.039 \\
\hline 509.236 & 509.348 & 0.112 & 909.446 & 909.336 & -0.110 \\
\hline 523.252 & 523.308 & 0.056 & 923.462 & 923.458 & -0.004 \\
\hline 565.260 & 565.344 & 0.084 & 965.470 & 965.491 & 0.021 \\
\hline \multicolumn{5}{|c|}{ Absolute Value Average Error: } & 0.053 \\
\hline
\end{tabular}


Table 4. Mass accuracy of representative product ions observed from the molecular ion of Substance $\mathrm{P}(\mathrm{m} / z$ 1347.7)

\begin{tabular}{|c|c|c|c|c|c|}
\hline \multicolumn{3}{|c|}{ MALD/I TOF-PSD } & \multicolumn{3}{|c|}{ MALD/I TOF-CID } \\
\hline $\begin{array}{l}\text { Expected } \\
m / z(D a)\end{array}$ & $\begin{array}{l}\text { Actual } \\
m / z(D a)\end{array}$ & $\begin{array}{c}\Delta m / z \\
(\mathrm{Da})\end{array}$ & $\begin{array}{c}\text { Expected } \\
m / z(D a)\end{array}$ & $\begin{array}{l}\text { Actual } \\
m / z(\mathrm{Da})\end{array}$ & $\begin{array}{c}\Delta m / z \\
(\mathrm{Da})\end{array}$ \\
\hline \multicolumn{3}{|l|}{ (a) } & \multicolumn{3}{|l|}{ (a) } \\
\hline 129.120 & 129.082 & -0.038 & 129.120 & 129.080 & -0.040 \\
\hline 226.170 & 226.108 & -0.062 & 226.170 & 226.082 & -0.088 \\
\hline 354.260 & 354.129 & -0.131 & 354.260 & 354.187 & -0.073 \\
\hline 451.320 & 451.338 & 0.018 & 451.320 & 451.243 & -0.077 \\
\hline 579.370 & 579.409 & 0.039 & 579.370 & 579.395 & 0.025 \\
\hline 707.430 & 707.292 & -0.38 & 707.430 & 707.356 & -0.074 \\
\hline 854.500 & 854.313 & -0.187 & 854.500 & 854.345 & -0.155 \\
\hline 1001.570 & 1001.696 & 0.126 & 1001.570 & 1001.572 & 0.002 \\
\hline 1058.590 & & & 1058.590 & 1058.592 & 0.002 \\
\hline 1171.680 & 1171.507 & -0.173 & 1171.680 & 1171.589 & -0.091 \\
\hline \multicolumn{3}{|l|}{1302.720} & 1302.720 & 1302.640 & -0.080 \\
\hline (b) & & & \multicolumn{3}{|l|}{ (b) } \\
\hline 157.110 & 157.029 & -0.081 & 157.110 & 157.053 & -0.057 \\
\hline 254.160 & 254.127 & -0.033 & 254.160 & 254.179 & 0.019 \\
\hline 382.260 & 382.197 & -0.063 & 382.260 & 382.234 & -0.026 \\
\hline 479.310 & 479.286 & -0.024 & 479.310 & 479.372 & 0.062 \\
\hline 607.370 & 607.168 & -0.202 & 607.370 & 607.227 & -0.143 \\
\hline 735.430 & 735.315 & -0.115 & 735.430 & 735.484 & 0.054 \\
\hline 882.490 & 882.292 & -0.198 & 882.490 & 882.447 & -0.043 \\
\hline 1029.560 & & & 1029.560 & 1029.388 & -0.172 \\
\hline 1086.580 & 1086.391 & -0.189 & 1086.580 & 1086.440 & -0.140 \\
\hline \multirow{3}{*}{$\begin{array}{l}1199.670 \\
1330.710\end{array}$} & & & \multicolumn{3}{|l|}{1199.670} \\
\hline & saturated & & 1330.710 & 1330.673 & -0.037 \\
\hline & Average Error: & 0.107 & & Average Error: & 0.070 \\
\hline
\end{tabular}

matrix and cationization agent used. The excellent agreement, demonstrated by the values of average error, is a demonstration of how robust the PEG993 calibration is for application with other polymer systems.

To demonstrate that PEG can be used as a calibrant for analytes other than synthetic polymers, a series of peptides were analyzed by both PSD and CID. To assess their mass accuracy, the product-ion masses for the peptides Substance P, angiotensin I, bradykinin, and angiotensin II were compared with values calculated from their known peptide sequences. Table 4 displays the mass accuracy of the a-type and b-type peptide product ions of Substance P (Figure 12) collected from both PSD and CID experiments. For each of the peptides studied, the a-series and b-series product ions

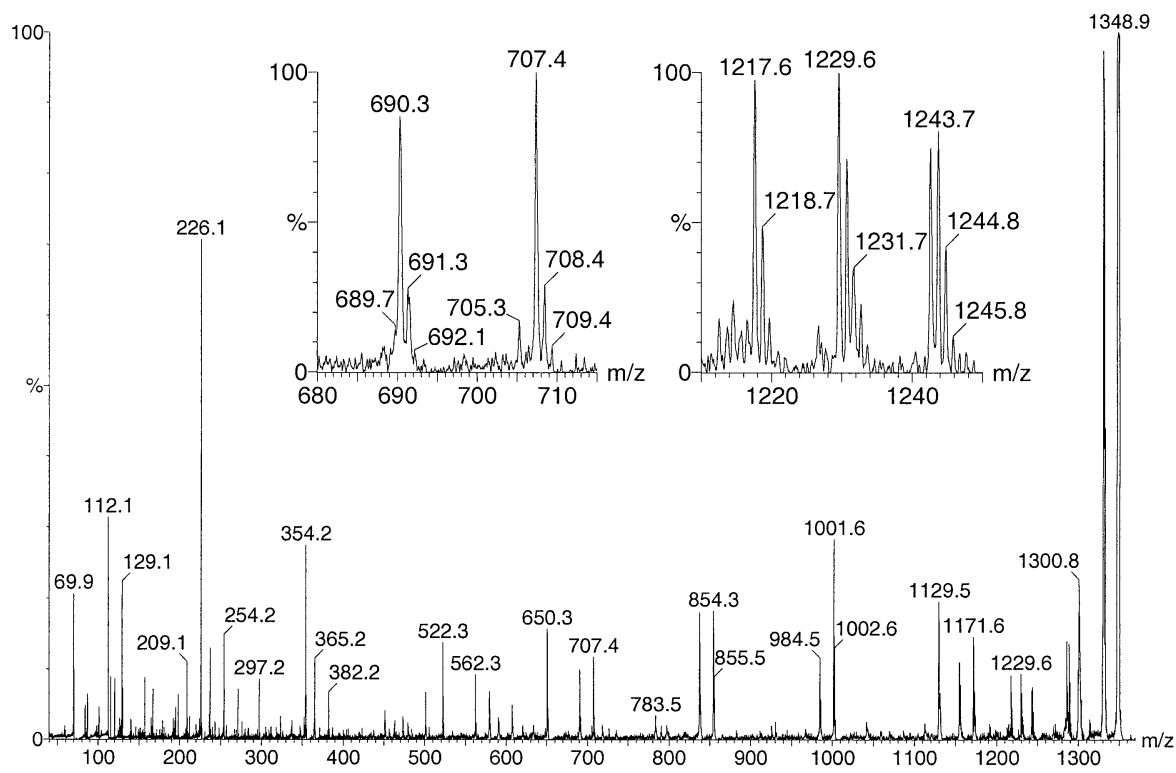

Figure 12. Stitched MALDI TOF CID spectrum of the protonated molecule of Substance P. 
Table 5. Mass accuracy of the $\left(\mathrm{a}-\mathrm{NH}_{3}\right)$ and $\left(\mathrm{b}-\mathrm{NH}_{3}\right)$ product ions observed from the molecular ion of Angiotensin II $(m / z$ 1046.5)

\begin{tabular}{|c|c|c|c|c|c|}
\hline \multicolumn{3}{|c|}{ MALD/I TOF-PSD } & \multicolumn{3}{|c|}{ MALD/I TOF-CID } \\
\hline $\begin{array}{l}\text { Expected } \\
m / z \text { (Da) }\end{array}$ & $\begin{array}{l}\text { Actual } \\
m / z(D a)\end{array}$ & $\begin{array}{c}\Delta m / z \\
(\mathrm{Da})\end{array}$ & $\begin{array}{c}\text { Expected } \\
m / z(\mathrm{Da})\end{array}$ & $\begin{array}{l}\text { Actual } \\
m / z(D a)\end{array}$ & $\begin{array}{c}\Delta m / z \\
(\mathrm{Da})\end{array}$ \\
\hline$\left(a-\mathrm{NH}_{3}\right)$ & & & $\left(a-\mathrm{NH}_{3}\right)$ & & \\
\hline $\begin{array}{l}71.014 \\
227.115\end{array}$ & & & $\begin{array}{r}71.0135 \\
227.1145\end{array}$ & 227.139 & 0.025 \\
\hline 326.183 & 326.134 & -0.048 & 326.1825 & 326.222 & 0.039 \\
\hline 489.247 & 489.278 & 0.031 & 489.2465 & 489.310 & 0.063 \\
\hline 602.331 & 602.492 & 0.161 & 602.3305 & 602.513 & 0.183 \\
\hline 739.390 & 739.409 & 0.019 & 739.3895 & 739.472 & 0.082 \\
\hline 836.442 & & & 836.4415 & & \\
\hline$\left(b-\mathrm{NH}_{3}\right)$ & & & $\left(b-\mathrm{NH}_{3}\right)$ & & \\
\hline 99.0085 & & & 99.0085 & & \\
\hline 255.1095 & 255.161 & 0.051 & 255.1095 & 255.241 & 0.131 \\
\hline 354.1775 & 354.176 & -0.002 & 354.1775 & 354.200 & 0.022 \\
\hline 517.2415 & 517.254 & 0.012 & 517.2415 & 517.285 & 0.043 \\
\hline 630.3255 & 630.402 & 0.077 & 630.3255 & & \\
\hline 767.3845 & 767.446 & 0.062 & 767.3845 & 767.551 & 0.167 \\
\hline \multirow[t]{2}{*}{864.4365} & & & 864.4365 & & \\
\hline & Average Error: & 0.052 & & age Error: & 0.084 \\
\hline
\end{tabular}

were used as representative ions that cover a broad mass range to assess the mass accuracy. Two of the peptides, bradykinin $(\mathrm{m} / \mathrm{z} 1060)$ and angiotensin II $(\mathrm{m} / \mathrm{z}$ 1046), have precursor-ion molecular weights that are near the precursor-ion molecular weight of the calibrant, PEG ( $m / z$ 993). For bradykinin, the average error (absolute value $\Delta m / z$ ) was $0.058 \mathrm{Da}$ for PSD and 0.045 for CID. For angiotensin II, the average error (absolute value $\Delta \mathrm{m} / \mathrm{z}$ ) was $0.051 \mathrm{Da}$ for PSD and 0.071 for CID. The other two peptides studied, Substance P $(\mathrm{m} / \mathrm{z}$ 1347) and angiotensin I ( $m / z$ 1296), have precursor-ion molecular weights that are above that of the calibrant by more than 300 Da. For Substance P, the average error (absolute value $\Delta \mathrm{m} / \mathrm{z}$ ) was $0.107 \mathrm{Da}$ for PSD and 0.070 for CID. For angiotensin I, the average error (absolute value $\Delta m / z$ ) was 0.053 Da for PSD and 0.082 for CID. As was the case with the polymers mentioned above, the absolute error (in Da) appears to be constant through the entire mass range for these peptides. Although the matrix was the same for the PEG calibrant and peptide analytes, the solvents used and the drying of the sample onto the surface of the probe were quite different. Also, the structural features of the PEG calibrant are quite different than the peptides. With these differences considered, the agreement between expected values and measured values across the entire mass range for product ions of these peptides demonstrates that PEG is a robust calibrant for peptides as well as synthetic polymers.

Although the product-ion mass accuracy for both polymers and peptides presented in these examples is quite good, there are a few peaks in each example that display a $\Delta \mathrm{m} / \mathrm{z}$ greater than $0.1 \mathrm{Da}$. The cause of the mass error for these peaks was investigated and, for an overwhelming majority of the peaks, the error could be rationalized by one of two explanations. First, some of the peaks had poor signal-to-noise ratio $(\mathrm{S} / \mathrm{N})$, and the low ion statistics could contribute to difficulty in accurate peak picking. Second, many of these peaks fell into a region of a particular segment where the resolution was poor (i.e., the low-mass end of a segment). The poor resolution can also lead to difficulty in peak picking, which can contribute to poor mass accuracy. It was mentioned above that the data acquisition software requires a reflectron voltage decrementation of $75 \%$ from segment to segment, which gives rise to the lower resolution peaks at the low-mass end of each segment. Setting the voltage decrement, instead, to $80 \%$ would likely improve the mass accuracy for these peaks that have adequate $S / N$, but suffer from poor resolution.

\section{Peptide Product-Ion Formation (-17 Da Peaks)}

In the MALDI PSD spectra of peptides, there are often additional series of peaks that are $17 \mathrm{Da}$ lower in mass than their corresponding a-series or b-series ions. These types of ions are also present in the PSD spectra reported here. One example of the expected and measured values for the product-ion series for angiotensin II is tabulated in Table 5. The expected values in Table 5 are the calculated values, assuming that the $17 \mathrm{Da}$ arises from a loss of $\mathrm{NH}_{3}$. For these types of ions, the average error (absolute value $\Delta \mathrm{m} / \mathrm{z}$ ) was found to be $0.052 \mathrm{Da}$ for PSD and 0.084 Da for CID. From the understanding of the precursor-ion selection mentioned above, information about the mechanism of the formation of the $-17 \mathrm{Da}$ ions can be inferred. From this data, we can conclude that the $\left(a-\mathrm{NH}_{3}\right)$ and $\left(b-\mathrm{NH}_{3}\right)$ peaks in the PSD and CID spectra of these peptides are a result of a two-step, post-source process and not the result of an in-source $\mathrm{NH}_{3}$ loss followed by a post-source fragmentation. If the latter were true, the product ions from 
the $\left(\mathrm{M}-\mathrm{NH}_{3}\right)$ peak (a lower mass ion not centered in the initial precursor-ion selection window) would not be mass calibrated correctly.

\section{Conclusion}

Several changes in operating conditions are reported here that result in the dramatic improvement of MALDI TOF CID and PSD, with regard to product-ion resolution and mass accuracy. The initial reflectron voltage (and subsequent voltages) was found to have a significant influence on the resolution of product ions. By decreasing the initial reflectron voltage (which automatically adjusts the subsequent segment voltages), improvement was seen in the resolution across each segment, in the overlap regions, and in the "stitching" capability. Taking care to center the precursor-ion with the precursor-ion selection window was also found to be important. Incorrect centering of the precursor-ion resulted in miscalibrated product ions. An awareness of this type of incorrect mass calibration for product ions led to a proposed interpretation of the $(\mathrm{a}-\mathrm{NH} 3)$ and (b - NH3) ions in the PSD and CID spectra of peptides. Coincidence peaks, whether they are noticeable or not, in the precursor-ion selection window, are a general problem for any type of analyte. This demonstration of the limitation of the timed-ion gate, points out the need to perform blank analysis. The setting of the beginning mass, which governs the acquisition mass ranges for the PSD (or CID) segments, was also found to have a significant influence on the mass accuracy of product ions. The importance of being consistent when setting up this parameter was demonstrated, and the ideal condition was found to be the setting where the starting mass is at or just below the precursor-ion mass.

With all parameters considered and using PEG993 as the calibrant, the mass accuracy of PSD and CID product ions was demonstrated with two polymer and four peptide samples. The absolute error (Da) for each test material was, on average, below 0.1 Da. A software limitation on the TofSpec2E instrument allows for only $75 \%$ decrementation of the reflectron voltage steps in PSD acquisition, which is beyond the focusing capability of the reflectron. This was demonstrated to limit the resolution of the lowest mass ions within each segment, and is a likely source of the slightly higher mass error for these peaks. A proposed change to smaller decrementation of the reflectron voltage (e.g., $80 \%$ decrementation), would likely lead to improved resolution across the segment mass ranges, and improved mass accuracy beyond what is reported here. In order to obtain PSD or CID data with good resolution and mass accuracy, care must be taken to be consistent with the setup of the conditions for calibration and analyte acquisition. These demonstrated improvements in MS/MS analysis capability are a benefit to workers who only have access to a MALDI TOFMS instrument with PSD capability, rather than a more expensive FT or Q-TOF type MS instrument.

\section{Acknowledgments}

The authors thank Mr. William Nichols (Eastman Kodak Company) and Dr. Scott D. Hanton (Air Products and Chemicals Incorporated) for valuable discussions. AJH gratefully acknowledges financial support from the Eastman Kodak Company.

\section{References}

1. Della-Negra, S.; Le Beyec, Y. New Method for Metastable Ion Studies with a Time of Flight Mass Spectrometer. Future Application to Molecular Structure Determinations. Anal. Chem. 1985, 56(11), 2035-2040.

2. Tang, X.; Ens, W.; Standing, K. G.; Westmore, J. B. Daughter Ion Mass Spectra from Cationized Molecules of Small Oligopeptides in a Reflecting Time-of-Flight Mass Spectrometer. Anal. Chem. 1988, 60(17), 1791-1799.

3. Tang, X.; Ens, W.; Mayer, F.; Standing, K. G.; Westmore, J. B. Measurement of Unimolecular Decay in Peptides of Masses Greater than 1200 Units by a Reflecting Time-of-Flight Mass Spectrometer. Rapid Commun. Mass Spectrom. 1989, 3(12), 443448.

4. Spengler, B.; Kirsch, D.; Kaufmann, R. Metastable Decay of Peptides and Proteins in Matrix-Assisted Laser-Desorption Mass Spectrometry. Rapid Commun. Mass Spectrom. 1991, 5(4), 198-202.

5. Spengler, B.; Kirsch, D.; Kaufmann, R.; Jaeger, E. Peptide Sequencing by Matrix-Assisted Laser-Desorption Mass Spectrometry. Rapid Commun. Mass Spectrom. 1992, 6(2), 105-108.

6. Spengler, B.; Kirsch, D.; Kaufmann, R. Fundamental Aspects of Postsource Decay in Matrix-Assisted Laser Desorption Mass Spectrometry. 1. Residual Gas Effects. J. Phys. Chem. 1992, 96(24), 9678-9684.

7. Hoteling, A. J.; Kawaoka, K.; Goodberlet, M. C.; Yu, W.-M.; Owens, K. G. Optimization of Matrix-Assisted Laser Desorption/Ionization Time-of-Flight Collision-Induced Dissociation Using Poly(ethylene glycol). Rapid Commun. Mass Spectrom. 2003, 17(14), 1671-1676.

8. Jackson, A. T. Exact Mass Tandem Mass Spectrometry of Low Molecular Weight Polymers. Proceedings of the 50th ASMS Conference on Mass Spectrometry and Allied Topics; Orlando, FL, June, 2002.

9. Kaufmann, R.; Spengler, B.; Luetzenkirchen, F. Mass-Spectrometric Sequencing of Linear Peptides by Product-Ion Analysis in a Reflectron Time-of-Flight Mass Spectrometer Using Matrix-Assisted Laser Desorption Ionization. Rapid Commun. Mass Spectrom. 1993, 7(10), 902-910.

10. Spengler, B. Post-Source Decay Analysis in Matrix-Assisted Laser Desorption/Ionization Mass Spectrometry of Biomolecules. J. Mass Spectrom. 1997, 32(10), 1019-1036.

11. Stimson, E.; Truong, O.; Richter, W. J.; Waterfield, M. D.; Burlingame, A. L. Enhancement of Charge Remote Fragmentation in Protonated Peptides by High-Energy CID MALDITOF-MS Using "cold" Matrixes. Int. J. Mass Spectrom. Ion Processes 1997, 169/170, 231-240.

12. Keough, T.; Lacey, M. P.; Youngquist, R. S. Derivatization Procedures to Facilitate de Novo Sequencing of Lysine-Terminated Tryptic Peptides Using Postsource Decay MatrixAssisted Laser Desorption/Ionization Mass Spectrometry. Rapid Commun. Mass Spectrom. 2000, 14(24), 2348-2356.

13. Jai-Nhuknan, J.; Cassady, C. J. Negative Ion Matrix-Assisted Laser Desorption/Ionization Time-of-Flight Post-Source Decay Calibration by Using Fibrinopeptide B. J. Am. Soc. Mass Spectrom. 1998, 9(5), 540-544.

14. Naven, T. J. P.; Harvey, D. J.; Brown, J.; Critchley, G. Fragmentation of Complex Carbohydrates Following Ionization by Matrix-Assisted Laser Desorption with an Instrument Fitted 
with Time-Lag Focusing. Rapid Commun. Mass Spectrom. 1997, 11(15), 1681-1686.

15. Gross, J.; Hillenkamp, F.; Wan, K. X.; Gross, M. L. Metastable Decay of Negatively Charged Oligodeoxynucleotides Analyzed with Ultraviolet Matrix-Assisted Laser Desorption/ Ionization Post-Source Decay and Deuterium Exchange. J. Am. Soc. Mass Spectrom. 2001, 12(2), 180-192.

16. Fournier, I.; Marie, A.; Lesage, D.; Bolbach, G.; Fournier, F.; Tabet, J. C. Post-Source Decay Time-of-Flight Study of Fragmentation Mechanisms of Protonated Synthetic Polymers Under Matrix-Assisted Laser Desorption/Ionization Conditions. Rapid Commun. Mass Spectrom. 2002, 16(7), 696-704.

17. Goldschmidt, R. J.; Wetzel, S. J.; Blair, W. R.; Guttman, C. M. Post-Source Decay in the Analysis of Polystyrene by MatrixAssisted Laser Desorption/Ionization Time-of-Flight Mass Spectrometry. J. Am. Soc. Mass Spectrom. 2000, 11(12), 10951106.

18. Przybilla, L.; Rader, H. J.; Mullen, K. Post-Source Decay Fragment Ion Analysis of Polycarbonates by Matrix-Assisted Laser Desorption/Ionization Time-of-Flight Mass Spectrometry. Eur. Mass Spectrom. 1999, 5(2), 133-143.

19. Puapaiboon, U.; Taylor, R. T.; Jai-Nhuknan, J. Structural Confirmation of Polyurethane Dendritic Wedges and Dendrimers Using Post Source Decay Matrix-Assisted Laser De- sorption/ Ionization Time-of-Flight Mass Spectrometry. Rapid Commun. Mass Spectrom. 1999, 13(6), 516-520.

20. Adhiya, A.; Wesdemiotis, C. Poly(propylene imine) Dendrimer Conformations in the Gas Phase: A Tandem Mass Spectrometry Study. Int. J. Mass Spectrom. 2002, 214(1), 75-88.

21. Lattimer, R. P. Tandem Mass Spectrometry of Lithium-Attachment Ions from Polyglycols. J. Am. Soc. Mass Spectrom. 1992, 3(3), 225-234.

22. Lattimer, R. P. Tandem Mass Spectrometry of Poly(ethylene glycol) Lithium-Attachment Ions. J. Am. Soc. Mass Spectrom. 1994, 5(12), 1072-1080.

23. Selby, T. L.; Wesdemiotis, C.; Lattimer, R. P. Dissociation Characteristics of $[\mathrm{M}+\mathrm{X}]+$ Ions $(\mathrm{X}=\mathrm{H}, \mathrm{Li}, \mathrm{Na}, \mathrm{K})$ from Linear and Cyclic Polyglycols. J. Am. Soc. Mass Spectrom. 1994, 5(12), 1081-1092.

24. Jackson, A. T.; Jennings, K. R.; Scrivens, J. H. Generation of Average Mass Values and End Group Information of Polymers by Means of a Combination of Matrix-Assisted Laser Desorption/Ionization-Mass Spectrometry and Liquid Secondary Ion-Tandem Mass Spectrometry. J. Am. Soc. Mass Spectrom. 1997, 8(1), 76-85.

25. Jackson, A. T.; Yates, H. T.; Scrivens, J. H.; Green, M. R.; Bateman, R. H. Matrix-Assisted Laser Desorption/IonizationCollision Induced Dissociation of Poly(styrene). J. Am. Soc. Mass Spectrom. 1998, 9(4), 269-274. 